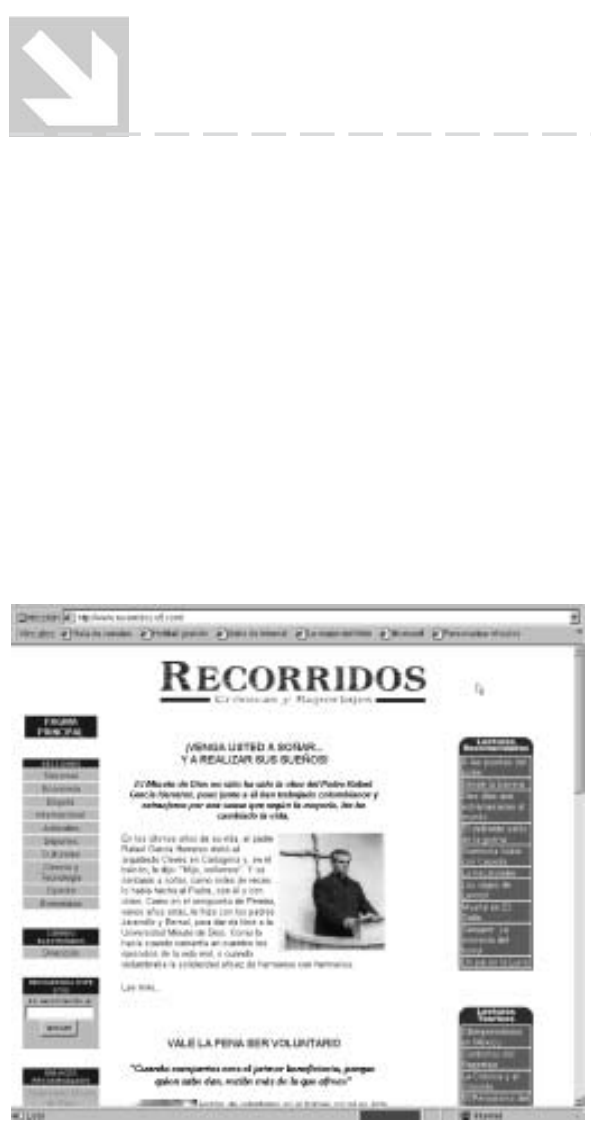

\title{
Sitios en Internet
}

\section{Agenda Recorridos www.recorridos.s5.com}

La necesidad de publicar las diferentes investigaciones y trabajos periodísticos de los estudiantes, dió como resultado un verdadero ambiente nootrópico que giraba en torno a la interpretación periodística y que vió, como novedosa herramienta, la posibilidad de crear un lugar en internet que tuviera la posibilidad de contarle al mundo cómo los futuros periodistas y administradores de los medios, desde hoy, ya tienen la posibilidad de hacer y narrar experiencias que hablan de comunicación y periodismo.

Es un sitio dado a luz en las clases de Periodismo Interpretativo, materia propia del pregrado en Comunicación Social - Periodismo de la Facultad de Comunicación Social de UNIMINUTO y dirigida por el profesor Arturo Rojas, impulsor de este sitio en internet. Una gran muestra del trabajo desarrollado por estudiantes con destreza para observar, analizar la realidad, involucrarse en ella y aportarle desde su experiencia humana y profesional.

En esta agenda se encuentran crónicas y reportajes con un sobrio sabor de lectura e investigación y está dedicada a todos aquellos que tienen sed de calma informativa, donde lo importante no se reemplaza por el ejemplar lanar y donde no hay afán por ganarle a la competencia. Se ocupa de temas que para muchos no son importantes pero que guardan siempre 'eso' que interesa y claro, bajo un estilo propio, comunitario, básico, simple y profundo.

Recorridos es, entonces, una excusa académica c'onde los protagonistas 


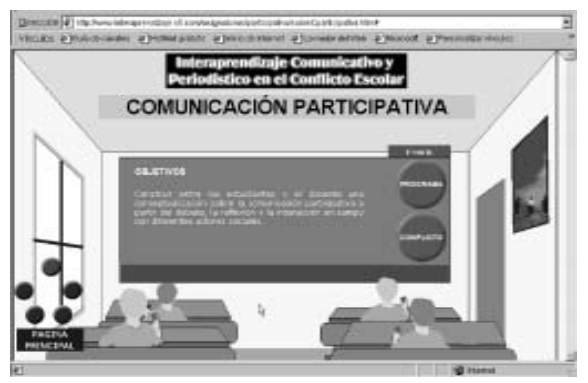

son los estudiantes. Ellos son los que dan vida al medio para procurar vencer desde las aulas, toda una amarilla patología que extrañamente evidencian quienes ya son profesionales de la comunicación.

\section{Interaprendizaje Comunicativo y Periodístico. www.interaprendizaje.s5.com}

Es un sitio web que se comporta como una alternativa de los llamados ecosistemas de aprendizaje. Creado con el fin de proyectar diferentes experiencias en varios espacios académicos, conjurados en uno sólo y especializado en procesos de interaprendizaje comunicativo y periodístico en el conflicto escolar desde investigaciones en Comunicación participativa, Investigación Acción Participativa (IAP), Psicología de la Comunicación, Periodismo Interpretativo, Periodismo Cívico y Periodismo Investigativo.

Bastante se ha hablado sobre educación y comunicación, pero lo novedoso de este portal es el análisis sobre el tema escolar desde las asignaturas antes mencionadas. En él se encuentran ejemplos de talleres sobre las experiencias, preguntas al navegante, respuestas en forma de análisis de realidad escolar, narraciones sobre conflictos sociales, políticos y culturales, hacen que este sitio se convierta en un importante lugar de encuentro de estudiantes con profesores y de estudiantes con sus compañeros.

La posibilidad de participar en la red desde las áreas arriba escritas, se pone de manifiesto en talleres interactivos, donde el usuario responde en línea y observa sus resultados. Todos bajo el cristal de la materia asignada, lo que desnuda una vez más, un profundo interés por buscar estrategias que mejoren los flujos comunicativos al interior de la comunidad académica escolar.

Interaprendizaje es proy cto salido de las clases de una especialización, pero pensado para mantenerse y convertirse en bibliografía de consulta 


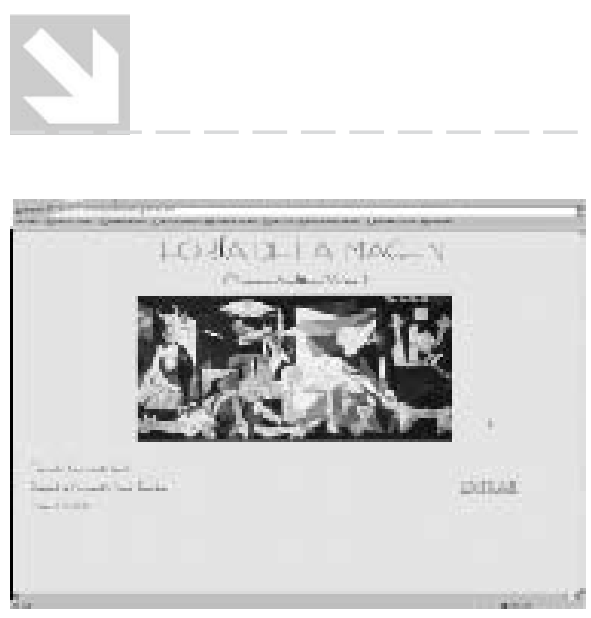

\section{Reseñas}

permanente por los actores del conflicto. Se olvida totalmente la idea de publicar por cumplir, pues la responsabilidad de los contenidos obliga a repensar cuáles serán los nuevos temas abarcados por estas seis materias para el interaprendizaje.

\section{Teoría de la imagen}

\section{www.uniminuto.edu/Teorimagen/ficha2.htm.}

Responde al compromiso, que existe en la Facultad de Ciencias de la Comunicación, de participar en la construcción de una educación diferente, en la cual los actores educativos se conviertan en sujetos de aprendizaje, y una manera de lograrlo es por medio de las tecnologías de la información.

En este contexto, la Facultad está empeñada en virtualizar las asignaturas de la tecnología en Comunicación Gráfica, el programa de Comunicación Social - Periodismo y la especialización en Comunicación Educativa, pero no para reemplazarlas, sino para que esos ambientes contribuyan a la formación de los estudiantes en la clase presencial.

Una de las asignaturas que comenzó este proceso fue la de Teoría de la Imagen (a cargo del profesor Fernando Gutiérrez), correspondiente a la tecnología y al pregrado. Aquí se pretende abrir un espacio virtual en el que se adquieran destrezas para apreciar lo que desde el principio y hasta el presente, el hombre ha desarrollado "a partir de la comunicación visual, compleja y sutil".

Al navegar por el sitio, el estudiante aprende a descubrir esas formas, pero ante todo, adquiere herramientas que le permiten, como comunicador, percibir, leer e interpretar los textos visuales. Ésta presenta una serie de contenidos que hablan sobre el concepto de imagen y de la histo"z $x$ de 


\section{ICon espiritu de callad}

\section{D ynminut?}

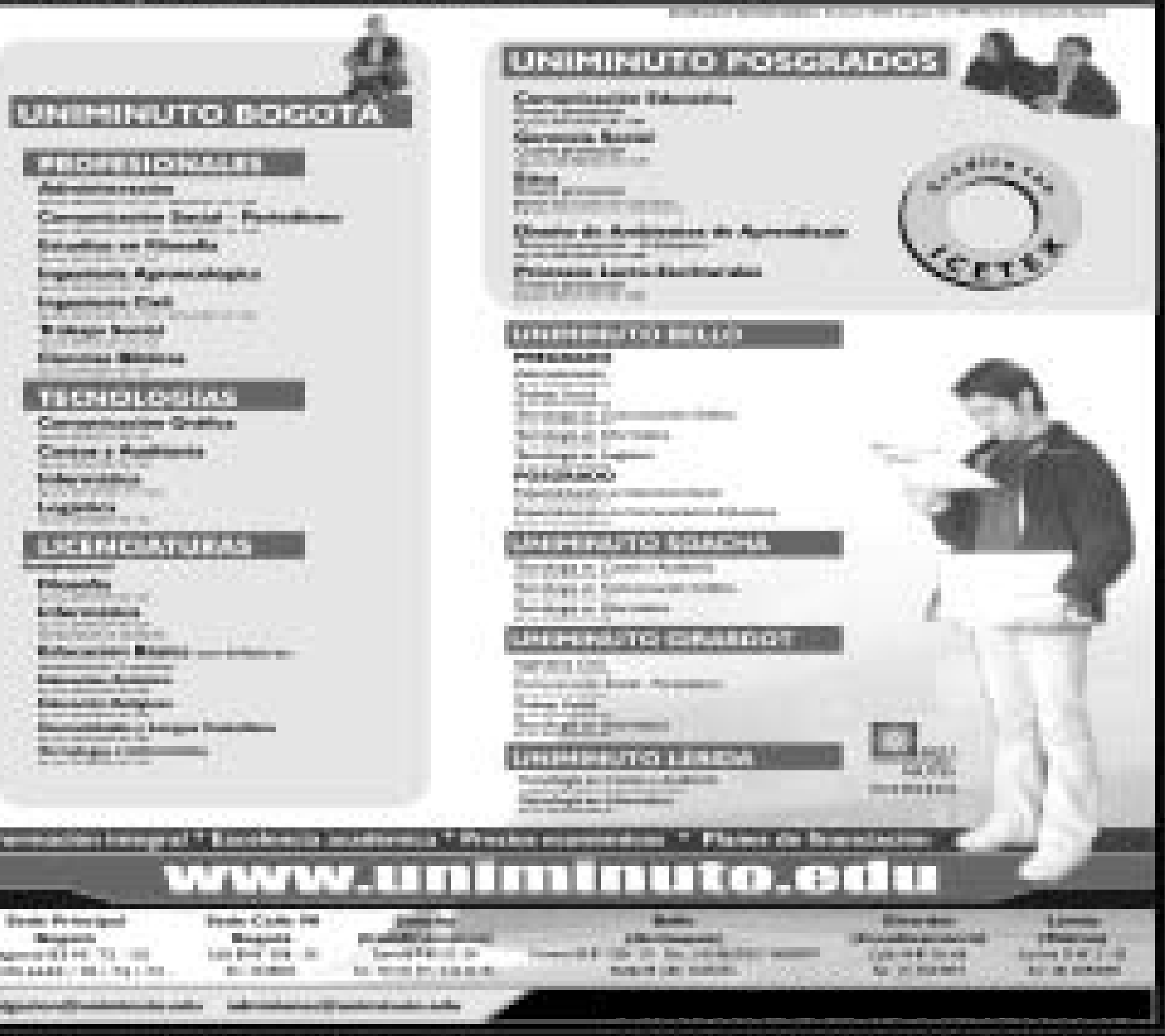

